\title{
La urbanización de la Villa 31 en su contexto: un estado de la cuestión de la rehabilitación del barrio de Retiro (2015-2019)
}

\section{Tomás Capalbo}

Licenciado en Sociología y maestrando en Políticas Ambientales y Territoriales por la Universidad de Buenos Aires. Actualmente es becario de posgrado y docente de la Universidad de Buenos Aires. Integra el Grupo de Estudios Ambientales dentro del Área de Estudios Urbanos del Instituto de Investigaciones Gino Germani. tomascapalbo94@gmail.com

\section{Federico Leandro Percossi Bossero}

Arquitecto y maestrando en Políticas Ambientales y Territoriales por la Universidad de Buenos Aires. Se ha desempeñado como docente en la Facultad de Arquitectura de la UBA, concretamente en las ramas de morfología, proyecto arquitectónico y planificación urbana.

federico.percossi@fadu.uba.ar

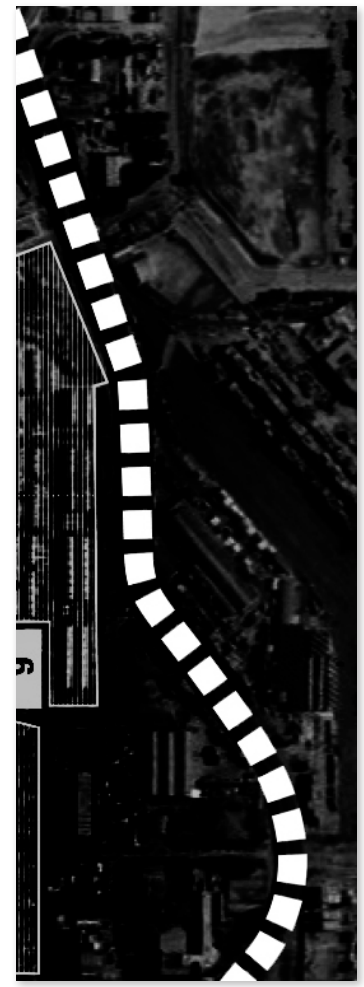

http://dx.doi.org/10.30972/crn.29294626 
La urbanización de la Villa 31 en su contexto: un estado de la cuestión de la rehabilitación del barrio de Retiro [2015-2019]

\section{Resumen}

La propuesta del artículo es indagar en torno a lo que se considera una novedad en el campo de las políticas públicas orientadas a las villas de la CABA: la coexistencia de urbanizaciones orientadas a promover la "integración" de barrios populares con megaproyectos públicos y privados de otra índole en zonas aledañas. Atendiendo uno de los casos que consideramos paradigmáticos a este respecto, se procede a situar el proceso de urbanización de la Villa 31 en el contexto de la rehabilitación del barrio de Retiro. En función de ello, se busca hacer una caracterización muy sucinta de los proyectos y políticas urbanísticas impulsados durante el período 2015-2019 en el barrio en cuestión, los cuales se pueden dividir de la siguiente manera: a) obras públicas tendientes a equipar, acondicionar y/o embellecer el área; b) venta de tierras públicas para el desarrollo inmobiliario y c) la integración de la Villa 31.

\section{Palabras clave}

Estado; urbanización de villas; rehabilitación urbana; políticas públicas.

\section{The urbanization of Villa 31 in its context: a state of the question of the rehabilitation of the Retiro neighborhood (2015-2019]}

\section{Abstract}

The proposal of the article is to investigate about what is considered a novelty in the field of public policies oriented to the slums of the CABA: the coexistence of urbanizations aimed at promoting the "integration" of popular neighborhoods with public and private megaprojects of other kinds in surrounding areas. Attending one of the cases that we consider paradigmatic in this regard, we proceed to situate the urbanization process of Villa 31 in the context of the rehabilitation of the Retiro neighborhood. Based on this, it seeks to make a very succinct characterization of the urban projects and policies promoted during the 2015-2019 period in the neighborhood in question, which can be divided as follows: a) public works aimed at equipping, conditioning and / or beautify the area; b) sale of public lands for real estate development and c) the urban integration of Villa 31.

\section{Key words}

State; urbanization of slums; urban rehabilitation; public policies.

\section{A urbanização da Villa 31 no seu contexto: um estado da arte da questão da reabilitação do bairro de Retiro [2015-2019]}

\section{Resumo}

A proposta do artigo é investigar o que se considera uma novidade no campo das políticas públicas voltadas para os municípios da CABA: a coexistência de urbanizações que visam promover a "integração" de bairros populares com megaprojetos públicos e privados de outra natureza nas áreas circundantes. Atendendo a um dos casos que consideramos paradigmáticos, passamos a situar o processo de urbanização da Villa 31 no contexto da reabilitação do bairro do Retiro. A partir disso, buscamos fazer uma caracterização muito sucinta dos projetos e políticas urbanas promovidos durante o período 2015-2019 no bairro em questão, que podem ser divididos da seguinte forma: a) obras públicas destinadas a equipar, condicionar e / ou embelezar a área; b) venda de terrenos públicos para o desenvolvimento imobiliário c) integração da Villa 31.

\section{Palavras-chave}

Estado; urbanização de vilas; reabilitação urbana; políticas públicas. 


\section{Introducción}

A lo largo del último quindenio el enfoque de las políticas públicas orientadas a los sectores populares de la Ciudad Autónoma de Buenos Aires (CABA) ha ido virando de forma sustancial. Durante el primer gobierno de Mauricio Macri (2007-2011), las políticas han llegado a ser categorizadas de "limpieza social" (Cravino y Palombi, 2015), entre otras cuestiones debido al desalojo de los recicladores urbanos, la expulsión de indigentes (GonZÁLEZ REDondo, 2014) $\mathrm{y}$ el constante desaliento a que se habite en las villas. En dicho período el por entonces jefe de gobierno porteño, "[llamó] al diálogo para erradicar la Villa 31" (Clarín, 04/08/2007). Es en este contexto, y a modo de respuesta, cuando se creó la Mesa por la Urbanización y Radicación de la Villa 31-31 bis: un espacio asambleario que nucleó a vecinos, organizaciones sociales y académicos. A partir de numerosos reclamos, los partidarios de la urbanización con radicación consiguieron, en el año 2009, la presentación y aprobación de la Ley N.$^{\circ}$ 3343, que dispuso la urbanización del barrio y estableció la creación de la Mesa de Gestión y Planeamiento (MGyP). Luego de dos años de trabajo, la MGyP envió un dictamen a la Legislatura, en el cual se definieron, entre otras cuestiones, criterios relacionados con apertura de calles, diseño de nuevas viviendas y mejoramiento de las existentes. Sin embargo, el gobierno de la ciudad dilató su tratamiento en la Legislatura, de manera que, si bien la ley que dispone la urbanización del barrio se mantuvo vigente, se obturó la aprobación de un plan integral.

A raíz de la resistencia ejercida desde las villas y luego de conflictos en distintos puntos de la urbe - como la toma del Parque Indoamericano (Cravino y PALOMBi, 2014), que lograron poner en cuestión el paradigma predominante-, durante el segundo gobierno de Macri (20112014) se modificó levemente el enfoque de las políticas. En efecto, comenzaron a delinearse iniciativas tendientes a proveer servicios e infraestructura en villas. Sin embargo, ante la falta de presupuesto destinado a tal fin y la precariedad de las soluciones brindadas en ausencia de un plan integral, dichas iniciativas fueron denominadas por el Ministerio Público Tutelar como "maquillaje urbano" (citado en Brikman, 2016). El dictamen para urbanizar la Villa 31, por su parte, permaneció en un estado de letargo.

El año 2015 constituyó un punto de inflexión en el campo de las políticas públicas destinadas a la villas de la CABA, en tanto se aprobaron las leyes N. ${ }^{\circ}$ 5798, 5705 y 5799, centradas en la "reurbanización, zonificación e integración social, cultural y urbana" de la villa Rodrigo 
Bueno, la Villa 20 y el Playón de Chacarita, respectivamente. A su vez, el gobierno local emitió el Decreto N. ${ }^{\circ} 363$ creando la Secretaría de Integración Social y Urbana (SECISYU) y otorgándole la responsabilidad de llevar adelante la urbanización de la Villa 31. En paralelo a estos procesos, florecieron un conjunto de iniciativas tanto públicas como privadas en zonas aledañas a las villas en cuestión. Como veremos a continuación, el caso de la Villa 31 resulta paradigmático en la medida en que su urbanización se da en paralelo a los siguientes fenómenos: una masiva privatización de tierras estatales en zonas aledañas; el impulso de una gran cantidad de obras públicas, entre las que se destacan el conector verde, el Paseo del Bajo y el Edificio-puente y c) la modificación estética del barrio de Retiro en su conjunto. Esta rehabilitación urbana, que al mismo tiempo se propone tanto "integrar social y urbanísticamente" una villa como impulsar megaproyectos públicos o privados de otra índole, constituye un enfoque novedoso en el campo de las políticas públicas de la CABA.

La propuesta de este artículo es situar el proceso de urbanización de la Villa 31 en un contexto más amplio: la rehabilitación del barrio de Retiro. El alcance del trabajo es de tipo exploratorio, en tanto constituye un primer acercamiento a un fenómeno que continúa en curso, y descriptivo, debido a que se propone como objetivo caracterizar de manera muy sucinta los proyectos y políticas urbanísticas impulsadas desde 2015 hasta 2019 en el barrio en cuestión. El abordaje metodológico utilizado fue de tipo mixto: se cuantificó el alcance de las privatizaciones de tierras a partir del análisis de fuentes secundarias, se realizó un relevamiento en un predio de nuevas viviendas construidas en el marco de la urbanización con el fin de conocer su estado edilicio y se realizaron entrevistas y observaciones participantes en la Villa 31 a lo largo de todo el período, que permitieron profundizar en un análisis cualitativo de la política de urbanización. El trabajo se estructura en dos apartados: en el primero se presentan algunas discusiones conceptuales sobre las nociones de estado, rehabilitación urbana y acumulación de capital; a continuación, en el segundo apartado, se profundiza en la caracterización de algunos de los proyectos impulsados en la zona de Retiro durante el período en cuestión.

\section{Consideraciones sobre la rehabilitación urbana: el rol del estado y la acumulación de capital}

El cambio de enfoque de las políticas públicas hacia las villas debe ser iluminado desde un marco teórico que permita poner en relación las transformaciones urbanas con algunas 
dinámicas económico-políticas. En ese sentido, la escuela francesa de sociología urbana ofreció dos líneas de análisis: por un lado, haciendo foco en el rol del estado en la urbanización capitalista; por el otro, examinando la relación entre modo de producción y espacio urbano. Sobre el primer punto, Topalov (1979) remarcó la necesidad de romper con el paradigma de la escuela clásica de sociología urbana (PARK, 1999) y dejar así de tomar al estado como variable independiente - como un agente externo-, para en su lugar pensarlo como una multiplicidad de dispositivos que realizan el interés general de la clase dominante. En cuanto a la segunda cuestión, CASTELls (1974, p. 15) señaló que "en una sociedad en la que el Modo de Producción Capitalista es el predominante, el sistema económico es el sistema dominante de la estructura social y, por consiguiente, el elemento de producción es la base de la organización del espacio".

Si bien resulta pertinente suscribir a la doble ruptura epistemológica que plantea la escuela francesa respecto de la escuela clásica a la hora de estudiar los fenómenos urbanos, es necesario abordar el caso complejizando la noción de estado y la relación entre modo de producción y ciudad. Al pensar al estado como una herramienta al servicio de la clase dominante, la escuela francesa perpetúa, bajo un manto de teoría crítica, el error de la escuela con la que intenta romper: la cosificación de aquel.

Lo interesante del caso bajo análisis es que, como veremos, el estado, en un mismo movimiento, aparece cediendo a demandas tanto populares — urbanizando una villa - como a los intereses de distintos capitales - liberando tierras al mercado-. Esto da cuenta de cierta porosidad del estado, tanto por abajo como por arriba, respectivamente. Es por ello que no debe ser pensado como una mera herramienta ni como un ente monolítico, sino como "un momento del desarrollo de la totalidad de las relaciones sociales, es decir, como una parte del desarrollo antagónico, y sujeto a la crisis de la sociedad capitalista” (HoLloway, 1993, p. 80). Así, es posible afirmar que la forma estado se encuentra determinada en gran medida por los requerimientos de la acumulación del capital, pero la manera en que se satisfacen o no tales requerimientos y sus consecuencias depende de una contingente y particular cristalización de correlación de fuerzas entre grupos sociales. A su vez, dichos requerimientos de la acumulación de capital no son constantes, de manera que no se puede concebir el modo de producción capitalista como algo fijo, sino que debe ser analizado atendiendo las fluctuaciones del patrón de acumulación. En este sentido, diversos autores advierten que desde la década de 1970 se asiste a una progresiva financiarización (ARRIGHI, 1999) de 
la economía global, cuyos efectos se materializan en distintos puntos de la urbe a través de procesos de privatización de tierras, del impulso de grandes proyectos urbanos público/privados financiados por organismos multilaterales de crédito y/o de la creación de burbujas inmobiliarias que culminan con diversos procesos de despojo (HARveY, 2014; Socoloff, 2015; Mignaqui, 2018).

Si bien las condiciones económico-políticas han cambiado, es necesario comprender que las transformaciones impuestas por el patrón industrialista persisten como huellas en la ciudad. CoRrea (1993, p. 2) identifica una "sincronía entre el emerger del capitalismo en su fase plenamente industrial y el surgimiento del área central”. Los centros se configuraron a partir de su capacidad de albergar un conjunto de actividades diversas en un lugar accesible. Retiro, a principios del siglo XX, se transforma en un territorio de ese tipo al conformarse como centro de transbordo donde se localizan gran parte de las terminales ferroviarias y como lugar neurálgico por su cercanía al puerto. En efecto, en dicho barrio se ubicaron depósitos, oficinas e industrias. En la década de 1930, un grupo de inmigrantes europeos, en su mayoría polacos que trabajaban como jornaleros en el puerto, se asentaron en tierras que hoy forman parte de la Villa 31 (Bellardi y De Paula, 1986). Con el transcurso del tiempo, las estaciones ferroviarias se deterioraron, un conjunto de depósitos y fábricas fueron abandonadas y la Villa 31 se consolidó como barrio popular. Es así como se fueron solapando los "tres aspectos de deterioro" identificados por Domínguez Roca (2005, p. 222):

físico (deterioro de los edificios, deterioro del espacio público), funcional (pérdida de actividades, reemplazo de actividades por otras de menor calidad) y social (empobrecimiento de la población; deterioro de las condiciones materiales de vida de la población local).

A pesar de su deterioro generalizado, Retiro conservó su función como centro de transbordo y su cercanía a los centros de toma de decisiones (políticos y económicos). Como consecuencia, una y otra vez se anunciaban proyectos con intenciones de "recuperarlo" que, sin embargo, no se concretaban. Tanto es así que entre 1955 y 1982, al igual que las demás villas de la capital federal, sufrió distintas políticas erradicatorias que alcanzaron su punto más álgido con la última dictadura cívico-militar de 1976 (OszLAK, 2017), la cual en sus primeros cuatro años de gobierno de facto redujo el número de familias en el territorio de 6000 a 40 (Bellardi y De Paula, 1986). Con los sindicatos intervenidos y la Federación de Villas y Barrios de Emergencia quebrada, actores que habían tenido un rol clave para generar resistencia durante las primeras erradicaciones, los villeros acudieron tanto a la 
Iglesia como a la justicia para frenar el avance de las topadoras. Un amparo impulsado por delegados de la Villa 31 y las denuncias públicas realizadas por la Pastoral de Villas de Emergencia pusieron freno a los desalojos, y las 40 familias que aún resistían en el lugar pudieron quedarse allí (Blaustein, 2006).

Una vez recuperada la democracia se produjo un paulatino repoblamiento del barrio, pero sufriría una nueva oleada de desalojos en el marco de la construcción de la autopista Illia en 1995. Una vez más los vecinos se organizaron, y si bien no pudieron detener la finalización de las obras, lograron disipar los rumores de la erradicación de la totalidad del barrio.

En algunos de estos proyectos la Villa 31 era omitida; en otros directamente se pensaba en su erradicación. Es recién en el año 2015 cuando comienza a implementarse el "Plan de Urbanización Integral Retiro-Puerto", con el objetivo explícito de rehabilitar la zona en cuestión. En términos de CuENYA (2012, p. 28), proyectos urbanos de esta índole producen al menos tres modificaciones claves en la estructura de la centralidad urbana: "una modificación en la rentabilidad de los usos del suelo; una modificación funcional y físico espacial de áreas centrales estratégicas; y una modificación de los mecanismos de gestión pública”. En relación con el primer punto, la autora se vale de la rent gap theory, de NeIL Sмітн (2012) para dar cuenta de cómo zonas deterioradas pero potencialmente valiosas por su accesibilidad se vuelven objeto de inversión tanto del capital fundiario como de los promotores inmobiliarios. Dicha inversión resulta redituable si va acompañada de las otras dos intervenciones: la reconfiguración de las funciones de la zona por otras de mayor estatus y su modificación estética. Para ello, como veremos en el apartado siguiente, el estado se constituye como un elemento indispensable del proceso, en tanto avala y/o impulsa un conjunto de iniciativas.

Mientras que para algunos actores la rehabilitación urbana puede ser una gran oportunidad de negocio, para otros grupos sociales puede significar el deterioro en las condiciones de vida (López-Morales et AL., 2015) e incluso el puntapié para un proceso de expulsión por distintas vías (Gonçalves Mendes, 2009). La posibilidad de pensar estos problemas en América Latina bajo el paraguas conceptual de gentrificación es un tema de debate recurrente (HerZer, 2008). En este punto, se coincide con CASGRain y JanoschKa (2013) en que dicha noción debe ser retomada atendiendo las especificidades del territorio y merece ser pensada de manera crítica. 
Se sostiene que es preciso pensar la urbanización de las villas de la CABA en el marco de los problemas planteados debido a tres razones fundamentales. En primer lugar, son procesos que se dan en paralelo a la valorización del suelo en zonas aledañas: como veremos, la Villa 31 es un caso paradigmático debido a las monumentales obras públicas impulsadas recientemente y la masiva venta de tierras en espacios contiguos. En segundo lugar, suponen la inclusión de vastos territorios a la lógica del mercado formal. Esto implica concebir la integración de la villa no solo en términos legales e infraestructurales, sino también -y sobre todo- con relación a cómo las tierras pueden incorporarse al mercado. Por último, son políticas que exacerban los mecanismos de acumulación por desposesión (DE ANGELIS, 2012; Harvey, 2004; Harvey, 2014) en la ciudad: desde la venta de espacios públicos para financiar las obras de urbanización hasta relocalizaciones compulsivas de la población por "necesidad proyectual", pasando por la permanente toma de deuda del gobierno local con organismos multilaterales de crédito que apoyan tales políticas.

\section{Análisis de los proyectos urbanos impulsados en el barrio de Retiro}

A fines del siglo XVII el gobernador de la provincia de Buenos Aires Agustín de Robles construiría al este de la ciudad de Buenos Aires, a escasos metros del río de la Plata y en los terrenos que hoy forman parte de la plaza San Martín, su casa de descanso conocida como "El Retiro" (Del Solar, 1999). Desde entonces el barrio se identificaría con el nombre de la residencia, y hasta principios del siglo XIX no se extendería más allá de sus confines. Durante la segunda mitad del siglo XIX, Retiro encararía tímidamente una primera etapa de renovación al inaugurarse, entre otros edificios, la primera estación del Ferrocarril Oeste en 1854. Sin embargo, es recién durante el primer quindenio del siglo XX cuando el barrio comienza a verse inmerso en una gran transformación, a partir de la construcción de la nueva estación de Retiro, que sobrevive, con leves modificaciones, hasta el día de hoy. Desde entonces se conserva como un lugar neurálgico de la ciudad de Buenos Aires, como centro de conexión con la periferia y, por ello, como uno de los barrios más transitados de la ciudad.

Como se dijo previamente, si bien conservó dicha función a lo largo del siglo XX, su estatus se modificó con el correr del tiempo pasando de ser el emblema de las clases acomodadas a percibirse por esta misma como un barrio signado por la degradación. Desde 2015 se vienen impulsando un conjunto de iniciativas tanto públicas como privadas con asidero en el barrio de Retiro. Con fines analíticos es posible dividirlas de la siguiente manera: a) 
obras públicas tendientes a equipar, acondicionar y/o embellecer el área; b) venta de tierras públicas para el desarrollo inmobiliario y c) la integración de la Villa 31. Como se verá a continuación, si bien es posible hacer esta distinción analítica en relación con los objetivos explícitos de cada uno de los proyectos, en la práctica son dimensiones que aparecen de manera yuxtapuesta. Para analizar cada una de estas intervenciones, el foco estará puesto en el rol del estado, en el modo en que intervienen diversos actores y en la apertura de nuevos nichos de acumulación.

\subsection{Obras públicas tendientes a equipar, acondicionar y/o embellecer el área: el Conector verde, el Paseo del Bajo y el Edificio-puente del BID}

Un sinnúmero de intervenciones estatales modificaron con gran celeridad la estética de Retiro. Desde la rehabilitación de las estaciones ferroviarias (de los trenes Mitre, San Martín y Belgrano), pasando por la llegada del subte E hasta la construcción de grandes edificios, como el Ministerio de Educación y el Polo Educativo Mugica. Pero sin lugar a dudas, uno de los proyectos más ambiciosos fue la creación de un parque en altura a través de la Ley N. ${ }^{\circ}$ 5733. Esta dispuso la conversión de la superficie de la autopista Illia que se eleva por encima de la Villa 31 en un conector verde, así como la apertura de una nueva bajada entre la Facultad de Derecho de la Universidad de Buenos Aires y el Centro de Exposiciones y Convenciones (ver mapa 1). Según cómo fue promocionado en diversos medios de comunicación (LA NACIÓN 24/10/2016; ConstruAR 02/03/2017), el conector verde se encuentra inspirado en el High Line de Nueva York: un parque en altura que, construido sobre las vías abandonadas de un tren, constituye actualmente uno de los principales puntos turísticos de la ciudad. A diez años de su construcción, el parque en altura neoyorquino contribuyó a valorizar enormemente las tierras aledañas, con efectos expulsivos sobre la clase trabajadora estadounidense que allí residía (NASHED, 2018; HaRvey, 2014).

En la antigua traza, la superficie de intervención sobre la autopista es de $73.182 \mathrm{~m}^{2}$, y bajo la traza, de $23.025 \mathrm{~m}^{2}$ (LPO 03/02/2018). Se prevé que un $25 \%$ de la superficie del conector verde esté destinado a vialidad (por ejemplo, a ciclovías) y el 75 \% restante a "espacio público”. Según la Ley 6129, un mínimo del 65 \% del "espacio público" estará destinado a "espacio verde" y un $5 \%$ estará habilitado para emprendimientos privados, como bares, cafés, restaurantes, cervecerías, heladerías, gimnasios e incluso canchas de tenis y práctica de golf. Esto implica la liberación de $3600 \mathrm{~m}^{2}$ para el mercado. Según cálculos del gobierno de la 
1. La autopista Illia marca la división entre la Villa 31 (próxima a la terminal de ómnibus) y la Villa 31 Bis (de data más reciente). La construcción de viviendas debajo de la autopista (dando lugar al sector denominado Bajo Autopista) fue dificultando la conexión entre ambos barrios. Actualmente se está llevando adelante la relocalización de las más de mil familias que comprenden Bajo Autopista al nuevo predio de YPF. ciudad, el corrimiento de la traza tendrá un costo de 28.000.000 de dólares, que provienen, en gran medida, de créditos acordados con el BID y con la Corporación Andina de Fomento (CAF). Aún no se sabe cuánto costará la implementación del proyecto del parque en altura, pero según consta en el Boletín Oficial de la Ciudad, en noviembre de 2019 se adjudicó un contrato de consultoría individual para su diseño por un monto de alrededor de 1.500 .000 pesos, que será abonado con un préstamo del BID.

Distintos argumentos se esgrimieron a favor y en contra de tal decisión. Los funcionarios de la SECISYU sostenían que la obra se hacía en beneficio de los vecinos de la villa, argumentando por un lado que sería un "pulmón verde" para el barrio, y por otro lado que derribaría la barrera que divide la villa en dos ${ }^{1}$ (Legislatura CABA, 26/09/2016). Sus detractores argumentaban que con esta decisión no solo habría que relocalizar a las familias que viven debajo del futuro conector verde, sino también a aquellos afectados por la nueva traza, y que esta inversión millonaria no estaba entre las prioridades de los habitantes del barrio. Lo cierto es que el avance en la construcción de la nueva traza, puntualmente de los pilotes, implicó la relocalización intempestiva de 118 familias del sector Cristo Obrero de la Villa 31, cuestión sobre la que nos detendremos más adelante. A pesar de la celeridad con la que se impulsó el proyecto, en el año 2018 el gobierno de la ciudad decidió suspender por dos años su finalización. Entre otros argumentos, se sostuvo que la demora se debía a "la priorización de otras obras viales que ya se están ejecutando" y que apuntan a generar una "verdadera revolución en el tránsito porteño" y que como "la autopista Illia está actualmente en funcionamiento, el corrimiento del inicio de las obras de la nueva traza no afecta al tránsito que circula por la actual Illia” (Perfil, 16/6/2018). De manera que se reconoce la innecesariedad en materia de transporte del proyecto de cambio de traza.

El Paseo del Bajo constituye otra de las grandes obras de infraestructura de la ciudad, y junto con el cambio de traza están entre las más costosas de la última década (LA NAción, 28/09/2018). Es un corredor vial de 7,1 kilómetros de largo que se extiende desde la autopista Buenos Aires-La Plata hasta la autopista Illia. Se construyó durante el período 20162019, y tuvo un costo de 650.000 .000 de dólares, de los cuales 400.000 .000 se obtuvieron a partir de una línea de crédito celebrada entre el gobierno nacional con la CAF. Si bien en un principio el contrato era solo entre las partes mencionadas, a partir de la Ley 6131 de la CABA, el gobierno local se comprometió a hacerse cargo de 175.000.000 de los 400.000.000 
de dólares. En este marco y como contraprestación del compromiso asumido, el gobierno nacional le transfiere al local (ambos del mismo color político) un total de doce inmuebles, de los cuales ocho se encuentran ubicados en el barrio de Retiro, incluida gran parte de la Villa 31.

Previamente a la transferencia de los inmuebles, el Tribunal de Tasaciones de la Nación procedió a realizar una valuación de estos. El hecho de incluir a gran parte del polígono perteneciente a la Villa 31 en este proceso llevó a que parte de sus pobladores lo vieran como un intento de vender sus tierras. Los medios de comunicación con una impronta opositora denunciaron que la "Villa 31 quedará en venta al mejor postor" (PÁGina 12, 13/06/2019), mientras que los medios con una postura más afín a la del oficialismo sostuvieron que las tierras de la parcela en cuestión "no serán vendidas a privados sino que se las transfirió la Nación a la Ciudad para que pudieran firmarse las escrituras de las futuras viviendas de los vecinos del barrio" (CLARín, 04/07/2019). Los otros siete inmuebles ubicados en Retiro se encuentran en zonas aledañas a la Villa 31, y se espera, con su venta, recaudar alrededor de U\$S 100.000.000 para amortizar la deuda contraída con la CAF.

Otro de los proyectos que ha llamado la atención de la opinión pública es el Edificio-puente del BID. Con su construcción se propone generar una conexión

tanto física como simbólica entre el Barrio 31 y el centro de la Ciudad Autónoma de Buenos Aires [y al mismo tiempo albergar] la nueva oficina de esa entidad, proyectándose la misma como la más grande y única de su tipo fuera de la sede principal en Washington D. C. (ANEXo DE LA LEY 6.130/2018 DEL GCBA, p. 1).

La propuesta, concretamente, consiste en una estructura edilicia de 200 metros de extensión aproximada que se levantará por encima de la nueva traza de la Autopista Illia y las vías ferroviarias con terminal en Retiro, de manera de conectar ambos extremos. La estructura albergará en su interior $3800 \mathrm{~m}^{2}$ de oficinas donde trabajarán aproximadamente 180 empleados. El resto de la superficie será destinada a la circulación peatonal y a la creación de "espacios verdes". Las superficies donde se implantará estaban bajo dominio del Estado Nacional y de la Ciudad Autónoma de Buenos Aires, por lo que se concedió el uso a la Agencia de Administración de Bienes del Estado (AABE), que luego transfirió de forma gratuita el espacio al BID para la construcción y usufructo del Edificio-puente por un plazo de 100 años. 


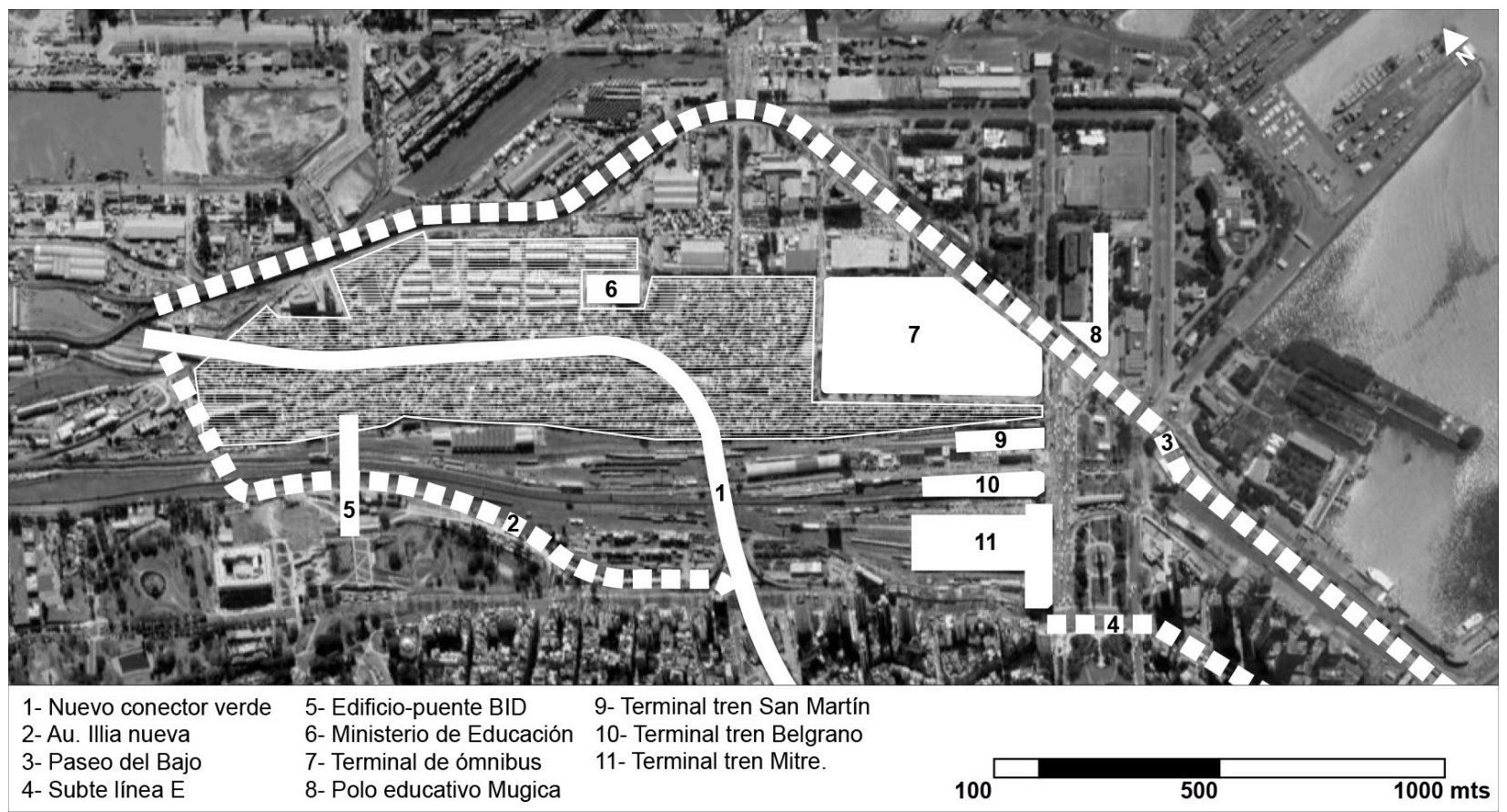

Mapa 1. Obras públicas

en el barrio de Retiro

Fuente: elaboración

propia con base en imágenes de Google

Earth

Ciertos sectores han manifestado su descontento con el proyecto, entre ellos un grupo de vecinos de la Villa 31. En el marco de la audiencia pública por el tratamiento de la ley en la Legislatura, uno de ellos supo sintetizar la postura del grupo:

Con respecto a la concesión del predio para el BID, una diputada de su partido, señora presidenta, decía que le iban a ceder el terreno porque la construcción la iba a hacer el banco. ¡Mire qué casualidad! Los vecinos ya construyeron las viviendas, ya las armaron las hicieron desde cero ¡Y no estaban los del BID o los de su partido! Fueron los vecinos quienes hicieron el barrio desde cero; fueron los vecinos los que llevaron los caños de agua de luz y las cloacas al barrio. ¡No fue 
ninguno de los bancos a los que ustedes pretenden darles la concesión a 100 años! ¿Por qué no les dan la concesión por 100 años a los vecinos? ¿Por qué no les dan gratis las viviendas a los vecinos? ¿Por qué les quieren cobrar a los vecinos? (Audiencia Pública 3/12/2018, p. 15).

Cabe resaltar el rol que se atribuye el BID como puente, tanto en términos simbólicos como materiales, entre dos grupos sociales. El organismo multilateral de crédito busca erigirse así como pieza fundamental de la integración, e intenta consolidar dicho imaginario a través de la construcción de una estructura perdurable. Las reservas planteadas por los vecinos en el marco de la audiencia pública, a su vez, llaman la atención sobre la peculiar decisión del gobierno de la ciudad de cederle el uso de la tierra por 100 años. Mientras que a los vecinos - quienes habitan un barrio casi centenario - se les cobrará la tierra en el marco de la urbanización, al BID se le otorga una cesión gratuita. Hay que detenerse en este punto: al cobrarle la tierra a los vecinos del barrio, el gobierno de la ciudad está partiendo de un paradigma que establece que la ocupación de los vecinos es ilegítima. A contrapelo de lo que dictan las leyes de urbanización, en la práctica el gobierno perpetúa el imaginario según el cual el villero habita de manera ilegal la ciudad.

\subsection{Venta de tierras públicas para desarrollo de emprendimientos privados: Quartier Retiro y Catalinas II}

Entre los emprendimientos inmobiliarios más publicitados se encuentra el Quartier Retiro, ubicado en el polígono delimitado por el Paseo del Bajo, Zanni y la Av. Ramón Castillo, cuya superficie se estima en $15.000 \mathrm{~m}^{2}$ (ver mapa 2). En dicho espacio había funcionado desde 1954 hasta 1999 el Hospital Ferroviario. El predio permaneció abandonado hasta que en 2008 Nicolás Caputo y un grupo de socios que conformaban Altos del Puerto consiguen una autorización de la Legislatura porteña para comprarlo en U\$S 6.000.000. Años más tarde, en 2016 y luego de que la rehabilitación de Retiro estuviera en marcha, el grupo consigue venderlo a Argencons por U\$S 23.000.000. En el proceso de refuncionalización de la zona, este capital fundiario logra hacerse con una ganancia de U\$S 18.000 .000 o, en términos porcentuales, del $283 \%$. Actualmente la desarrolladora Argencons se encuentra construyendo allí tres edificios que albergarán $32.400 \mathrm{~m}^{2}$ de oficinas corporativas premium, 492 unidades residenciales, estacionamientos para 427 vehículos y un paseo comercial. El Quartier recibió 62.000 .000 de dólares de inversiones, de los cuales la mitad proviene del blanqueo de capitales (TieMPO ARGENTINo, 20/05/2017). 
Con una impronta similar, Catalinas Norte II se encuentra emplazado en donde fuera un área operativa ferroviaria de la línea General Roca, lindera al Paseo del Bajo. Fue vendido por el gobierno de la CABA luego de un convenio que firmara con la AABE y el Ministerio de Transporte de la Nación en noviembre de 2016. El paso siguiente fue la promulgación de la Ley 5796 de CABA, en el año 2017, en la cual se dispone la desafectación, enajenación y subasta del polígono.

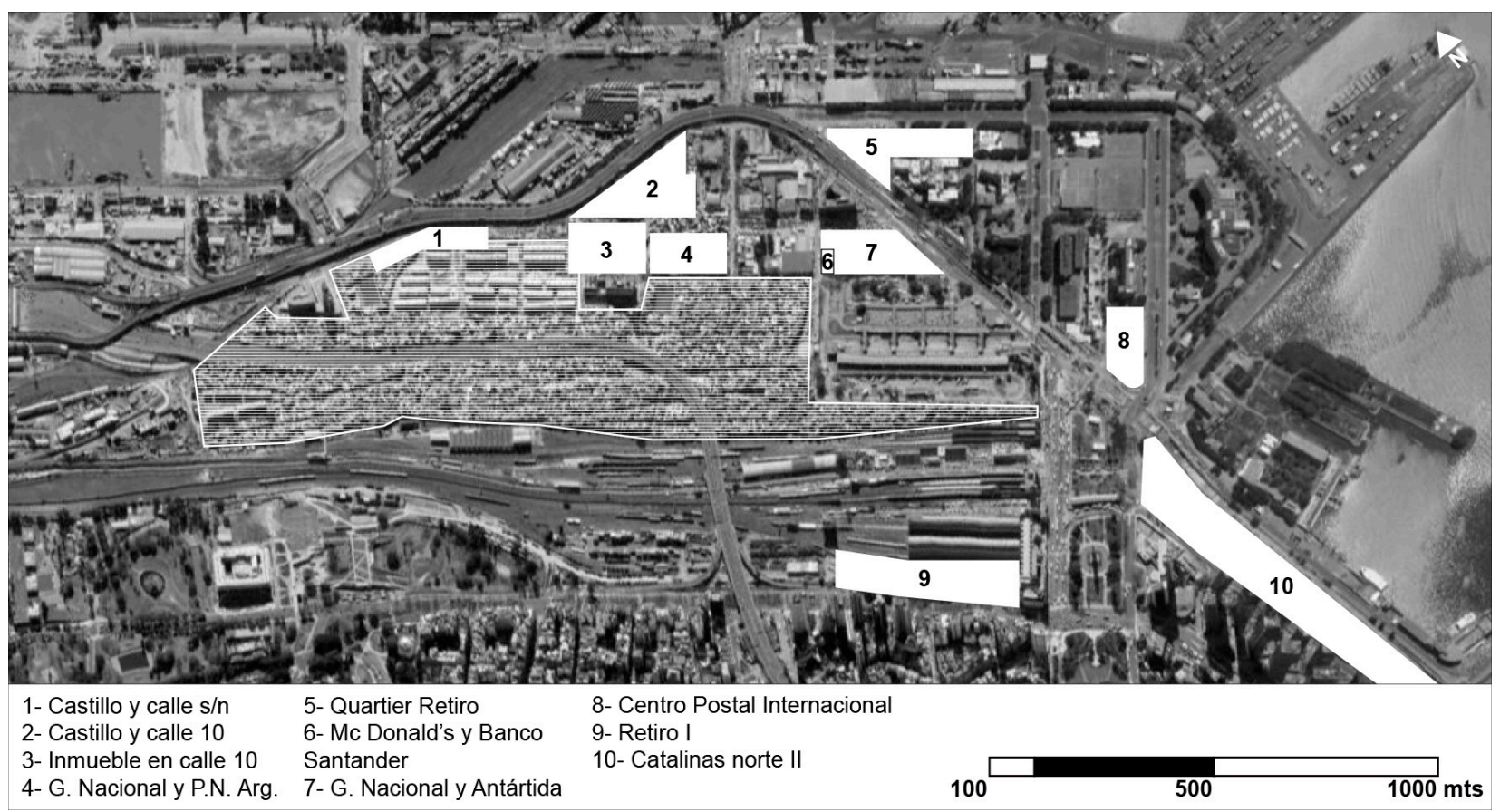

Mapa 2. Tierras subastadas/para subastar del barrio de RetiroFuente: elaboración propia con base en imágenes de Google Earth 
El predio tiene $128.223 \mathrm{~m}^{2}$ totales, de los cuales se destinarán $88.255 \mathrm{~m}^{2}$ a espacio público y $39.968 \mathrm{~m}^{2}$ fueron enajenados y subastados. Los fondos obtenidos por los remates, por un total de u\$s 269,375 millones, serán destinados a financiar el $50 \%$ de la obra del Paseo del Bajo. Para ser subastado, el predio fue dividido en ocho parcelas, siete de las cuales ya tienen dueño: tres pertenecen a la firma Consultatio Argentina SAU, dos a Fideicomiso BAP, una a TGLT (empresa fusionada con la constructora Caputo) y una a Santa María SAIF (empresa financiera de la organización Techint). Los parámetros constructivos que las leyes proponen -edificios de perímetro libre con planos límite de altura de 62 y $139 \mathrm{~m}$ y un basamento comercial de $8 \mathrm{~m}$ - evidencian una continuación de la morfología urbana de la zona de Puerto Madero hacia el resto de los bordes costeros de la ciudad.

En septiembre de 2019, a través del Decreto 518/2019, el gobierno nacional autorizó la venta del predio Centro Postal Internacional del Correo Argentino ubicado en la intersección Av. Antártida Argentina y Comodoro Py. Dicho predio tiene una superficie de $13.000 \mathrm{~m}^{2} \mathrm{y}$, según desarrolladores privados, su valor se estima en U\$ 17.000 .000 (INFobae, 02/03/2020).

A escasos metros del polígono de la Villa 31, a su vez, se liberaron tierras para la inauguración de una sede del banco Santander Río, por un lado, y para la apertura de un local de Mc Donald's, por el otro. Ambas iniciativas fueron anunciadas como parte de la "integración de la Villa 31" que promueve el gobierno de la ciudad en el marco de la urbanización.

En conjunto, si a los proyectos mencionados en este subapartado les sumamos tanto aquellos predios que subastar en el marco del convenio con la CAF como las cesiones a privados que se otorgan en espacios públicos señalados en el subapartado anterior, el estado impulsó en los últimos años la liberación de 206.943,7 $\mathrm{m}^{2}$ para el desarrollo de emprendimientos privados en el barrio de Retiro (ver tabla 1). 
Tabla 1

\begin{tabular}{|c|c|c|}
\hline & $\begin{array}{c}\text { Sup. que } \\
\text { subastar, } \mathbf{m}^{2}\end{array}$ & Aclaraciones \\
\hline \multicolumn{3}{|l|}{ Subastados } \\
\hline Catalinas Norte II (etapa 1) & $23.093,4$ & $\begin{array}{l}\text { Sumatoria del total de } \\
\text { los lotes de la etapa } 1\end{array}$ \\
\hline Quartier Retiro & $9.144,0$ & $\begin{array}{l}\text { Superficie ocupada por el ex } \\
\text { Hospital Ferroviario. Calculada } \\
\text { según mapeo propio. }\end{array}$ \\
\hline Mc Donald's y Banco Santander & 490,0 & $\begin{array}{l}\text { Superficie calculada según } \\
\text { mapeo propio. }\end{array}$ \\
\hline \multicolumn{3}{|l|}{ Para subastar } \\
\hline Nuevo conector verde & $2.744,3$ & $\begin{array}{l}\text { Superficie disponible para } \\
\text { concesión }\end{array}$ \\
\hline Bajo autopista & $23.025,0$ & $\begin{array}{l}\text { Superficie disponible para } \\
\text { concesión }\end{array}$ \\
\hline Retiro I & $5.413,0$ & $\begin{array}{l}65 \% \text { a espacio público } \\
\left(17.643 \mathrm{~m}^{2}\right)\end{array}$ \\
\hline Catalinas Norte II (etapa 2) & $18.429,0$ & - \\
\hline $\begin{array}{l}\text { Gendarmería Nacional y } \\
\text { Antártida Argentina }\end{array}$ & $15.720,0$ & - \\
\hline $\begin{array}{l}\text { Gendarmería Nacional y } \\
\text { Prefectura Naval Argentina }\end{array}$ & $14.229,0$ & - \\
\hline Inmueble ubicado en calle N.$^{\circ} 10$ & $21.468,0$ & - \\
\hline Av. Pte. Ramón Castillo y calle N. ${ }^{\circ} 10$ & $26.419,0$ & - \\
\hline Av. Pte. Ramón Castillo y calle s/n & $33.769,0$ & - \\
\hline $\begin{array}{l}\text { Centro Postal Internacional } \\
\text { del Correo Argentino }\end{array}$ & $13.000,0$ & - \\
\hline Total & $206.943,7$ & \\
\hline
\end{tabular}

Fuente: elaboración propia sobre la base de datos oficiales 


\subsection{Urbanización de la Villa 31}

La creación de la la SECISYU a fines del año 2015 reconfiguró el conflicto en torno a la urbanización de la Villa 31. El antagonismo que surcó el decenio anterior se caracterizó por el desarrollo de dos posturas claramente marcadas: la del partido de gobierno de la ciudad, que osciló entre posicionamientos erradicatorios y el simple abandono, y la urbanizadora, que nucleó a vecinos organizados, académicos e integrantes de numerosas organizaciones sociales. Con la asunción de Rodríguez Larreta y el viraje en relación con las políticas destinadas a las villas de la ciudad, la disputa pasó a centrarse en cómo debía urbanizarse el barrio y de qué manera iba a participar la población en dicho proceso (CAPALBo, 2019).

En este nuevo escenario, el mapa de actores se complejizó, y los límites entre los grupos sociales otrora enemistados se volvieron sumamente difusos. Al adoptar un discurso con tintes algo más progresistas, el partido que gobierna la ciudad supo seducir a una buena parte de vecinos organizados y logró construir lazos con algunas organizaciones sociales. Los grupos que mantuvieron una posición menos conciliadora, por su parte, manifestaron su descontento con la política de urbanización a través de movilizaciones, escraches, tomas al edificio de la SECISYU, entre otras acciones colectivas.

Desde sus albores, la SECISYU impulsó una serie de proyectos, entre los cuales se destacan el mejoramiento de viviendas existentes, la construcción de vivienda nueva, el mejoramiento de infraestructura para la provisión de servicios (agua potable, tendido eléctrico y cloacas), la rehabilitación de espacios públicos (fundamentalmente plazas, pero también canchas de fútbol) y el diseño de una nueva ley de urbanización (N. ${ }^{\circ}$ 6129). Los procesos que más resistencia generaron a lo largo de estos cuatro años fueron aquellos ligados a la relocalización de las manzanas 12 y 104 (desde Cristo Obrero al nuevo sector de Containera) y el reasentamiento de Bajo Autopista a un nuevo predio que se construyó en el sector de YPF (ver mapa 3). Las críticas se centraron en la falta de participación viabilizada para la población afectada en relación con los plazos, la manera en que debía llevarse adelante el reasentamiento y los métodos constructivos utilizados en las nuevas viviendas. En ambos se gestaron procesos asamblearios de población que relocalizar, que a partir de acciones directas (movilizaciones, escraches a funcionarios) y de diversos reclamos (a través de informes y notas en medios de comunicación) lograron fijar pisos de negociación (para profundizar en el conflicto y las estrategias de resistencia de los relocalizados ver CAPALBO ET AL., 2020). 
El proceso mediante el cual se relocalizó a las 118 familias de la 12 y 104 se hizo en tan solo seis meses, y culminó con el desalojo vía decreto del Ejecutivo de una familia que aún no estaba satisfecha con las condiciones de habitabilidad que le ofrecía el gobierno. A partir de un relevamiento realizado en las nuevas viviendas de Containera, se pudo observar que, a tan solo dos años de su construcción se encuentran en pésimas condiciones edilicias. En las viviendas denominadas emplaque, donde vive un tercio de la población relocalizada (mientras que las denominadas agrupadas, con otra tipología constructiva, alberga al resto), el ciento por ciento de los encuestados hizo al menos una vez un reclamo a la secretaría por problemas con su nueva vivienda. La gran mayoría de las viviendas (el $74 \%$ ) posee filtraciones. En algunos casos son de tal magnitud que llegan a generar inundaciones que provocan pérdidas materiales. Otro de los problemas compartidos por la mayoría (70 \%) tiene que ver con una deficiente instalación sanitaria. Se denunciaron desde problemas de nivelación de las bañeras hasta toilettes que quedaron inutilizados por múltiples problemas, pasando por olores de viviendas aledañas que se filtran por la ventilación. Más de la mitad de la población tiene problemas actualmente con la instalación eléctrica y con las aberturas (puertas, ventanas y herrería exterior). El 52 \% tiene dificultades con la cocina que le fue entregada por el organismo en el momento de su mudanza. Aquellos que manifestaron no tener dicho problema actualmente fue porque cambiaron la cocina o porque el organismo les consiguió una nueva. De manera que todas las cocinas que fueron entregadas en el momento de la relocalización, y que fueron contempladas como parte de la negociación, tuvieron fallas de fábrica. El $13 \%$ de las viviendas relevadas cuenta con fisuras en sus paredes. A pesar de las múltiples fallas, se prevé que los vecinos paguen por sus viviendas mediante un plan de financiación por cuotas diseñado por el gobierno de la ciudad. Actualmente los vecinos realizan reclamos con el objetivo de que el organismo reconozca y arregle las fallas en la construcción.

El proceso de relocalización de Bajo Autopista, por su parte, comenzó durante agosto de 2019 y aún continúa en curso. Tal como sucedió en la 12 y 104, las familias no pudieron elegir el material constructivo de las viviendas que van a habitar ni fueron partícipes de su diseño. Con los problemas edilicios del predio de Containera como antecedente, muchas familias se niegan a mudarse a las nuevas viviendas. En este contexto, el organismo utiliza diversos métodos de hostigamiento para empujar a las familias a mudarse: la zona se encuentra liberada por las noches y los vecinos sufren a diario problemas de inseguridad, durante el día - contra todo protocolo - la retroexcavadora demuele viviendas aledañas a las que siguen habitadas, lo que genera fisuras y filtraciones y, finalmente, se encuentran 
viviendo entre escombros y basura. Frente a estas acciones las familias se organizan en asamblea, llevan sus reclamos al ámbito de participación, presentan notas por escrito al organismo e incluso impulsaron dos medidas judiciales.

Para llevar adelante los proyectos mencionados, la SECISYU contó con un presupuesto sumamente abultado. Mientras que el Instituto de Vivienda de la Ciudad (IVC) que tuvo bajo su órbita la urbanización de seis villas (Rodrigo Bueno, Playón Chacarita, Villa 20, Villa 21/24, Villa 1-11-14 y Lamadrid) contó con un presupuesto de \$ 8.235.795.807 entre 2017 y 2019 inclusive, el presupuesto de la SECISYU, organismo creado ad hoc para urbanizar la Villa 31, ascendió a \$10.546.295.341 en el mismo período. Es necesario remarcar, a su vez, la incidencia que han tenido los organismos multilaterales de crédito en el caso de la 31, a diferencia de lo

Mapa 3. Sectores de la Villa $31 / 31$ bis.

Fuente: elaboración propia con base en imágenes de Google Earth

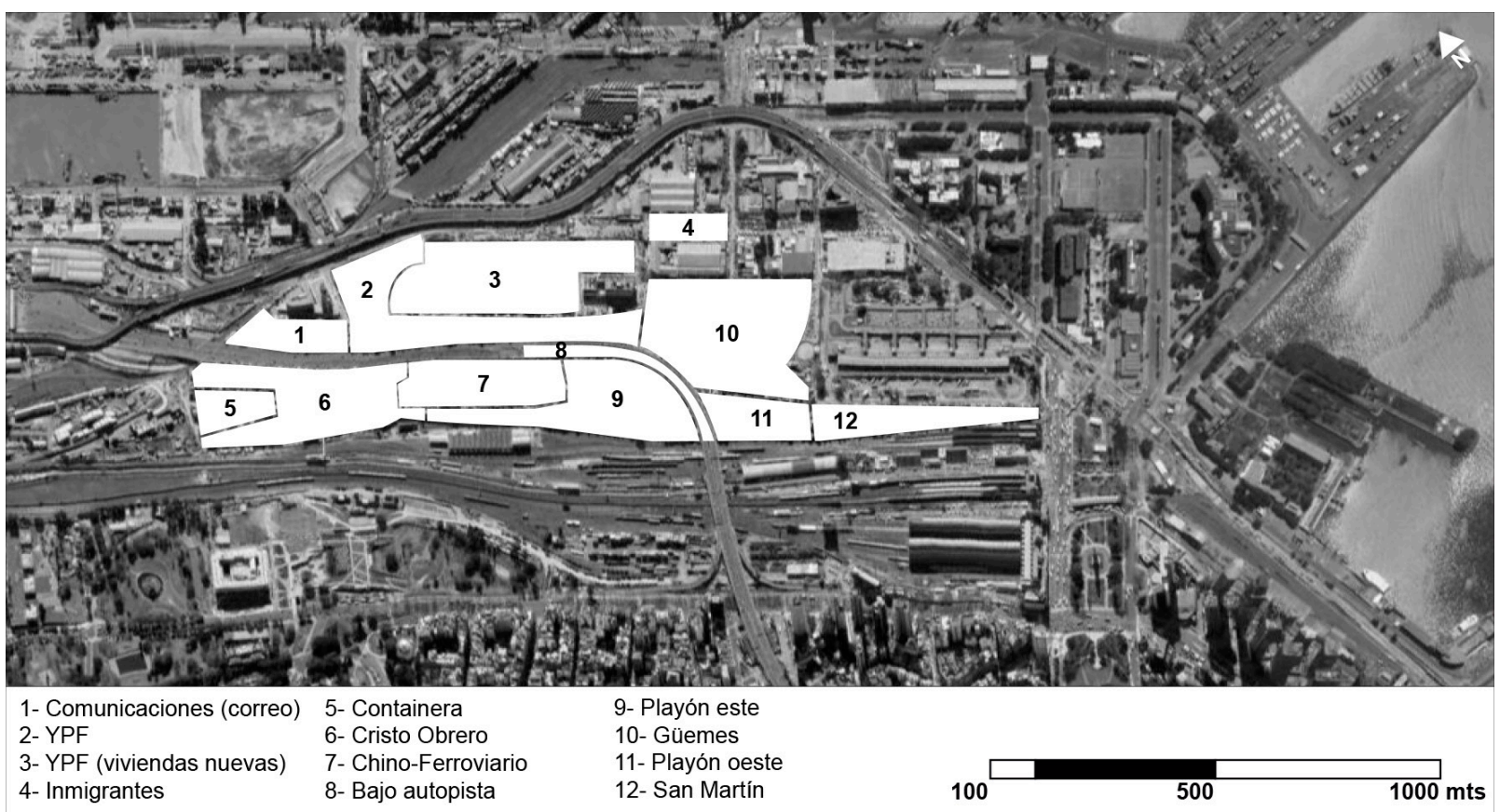


acontecido en el resto de las villas de la ciudad. Del monto otorgado a la SECISYU en el período indicado, el 69,38 \% corresponde a financiamiento externo (del BID y el BM). En el IVC, por su parte, el total presupuestado corresponde a fondos del tesoro de la Ciudad, recursos propios y transferencias internas, es decir que no contó con financiamiento externo.

La celeridad con la que se impulsó la urbanización de la Villa 31 y el presupuesto colosal asignado para tal fin deben enmarcarse en la rehabilitación del barrio de Retiro en general. En efecto, la nueva ley de urbanización N. ${ }^{\circ} 6129$ impulsada por el Ejecutivo habilita, en su artículo N. ${ }^{\circ}$ 44, a cualquier privado a hacerse con parcelas por un valor equivalente al de tres hipotecas. A su vez, en el artículo 50, incentiva el desarrollo de emprendimientos privados liberando las restricciones de usos del suelo a todo aquel que acceda a terrenos a través de subastas públicas o remates. Finalmente, el actual modelo de escritura (Resolución N. ${ }^{\circ}$ 204/SECISYU/19) pone en riesgo el derecho al arraigo de la población al habilitar la ejecución hipotecaria de una vivienda ante el no pago de tres cuotas de servicios (agua, luz o ABL), por un lado, y al instrumentar letras hipotecarias que en un futuro podrían permitir la transferencia de las carteras de crédito hacia manos privadas. En caso de que

Tabla 2

Incidencia del financiamiento externo (FE) en IVC y SECISYU

\begin{tabular}{|c|c|c|c|c|c|c|}
\hline \multirow[b]{2}{*}{ Año } & \multicolumn{3}{|c|}{ IVC* } & \multicolumn{3}{|c|}{ SECISYU } \\
\hline & $\begin{array}{c}\text { Presupuesto } \\
\text { Total }\end{array}$ & $\begin{array}{c}\text { Financiamiento } \\
\text { externo }\end{array}$ & \% F.E. & $\begin{array}{c}\text { Presupuesto } \\
\text { Total }\end{array}$ & $\begin{array}{c}\text { Financiamiento } \\
\text { externo }\end{array}$ & \% F. E. \\
\hline 2017 & $\$ 2.093 .467 .690$ & $\$ 0$ & $0,00 \%$ & $\$ 1.498 .068 .183$ & $\$ 724.000 .000$ & $48,33 \%$ \\
\hline 2018 & $\$ 2.920 .080 .000$ & $\$ 0$ & $0,00 \%$ & \$ 3.519.824.352 & $\$ 2.042 .895 .998$ & $58,04 \%$ \\
\hline 2019 & $\$ 3.222 .248 .117$ & $\$ 0$ & $0,00 \%$ & $\$ 5.528 .402 .807$ & $\$ 4.550 .244 .529$ & $82,31 \%$ \\
\hline \multirow[t]{2}{*}{ Total } & \$ 8.235.795.807 & $\$ 0$ & $0,00 \%$ & \$ 10.546.295.341 & \$ 7.317.140.527 & $69,38 \%$ \\
\hline & \multicolumn{2}{|c|}{$\begin{array}{l}\text { * Programa "Reintegración, } \\
\text { integración y transformación } \\
\text { de villas" }\end{array}$} & & & & \\
\hline
\end{tabular}

Fuente: elaboración propia sobre la base de datos oficiales 
se mantengan estas condiciones y no se impulsen instrumentos urbanísticos y políticas socioeconómicas que promuevan la radicación de sus habitantes o resguarden el polígono para vivienda social, la villa podría verse inmersa en una vorágine de sustitución paulatina de su población, como sucedió con otros barrios populares de América Latina (MAKHLOUF DE LA GARZA, 2015).

\section{Conclusiones}

A lo largo de este trabajo nos propusimos analizar la rehabilitación urbana del barrio de Retiro a la luz de tres dimensiones de análisis: el rol del estado, la apertura de nuevos nichos de acumulación y la modalidad de intervención de algunos actores, entre ellos los organismos multilaterales de crédito. En relación con el rol del estado, vimos cómo se impulsó un conjunto de obras públicas que permitieron renovar la estética de Retiro con gran celeridad, a la vez que se canalizaron demandas populares en la medida en que se promovió la integración de la Villa 31. Si bien la política de urbanización del barrio popular implicó un avance en términos de provisión de servicios, viene topándose con resistencia de amplios sectores debido tres razones fundamentales: la falta de participación de la población en su implementación, la calidad y el material utilizado para la construcción de las nuevas viviendas sociales construidas por el gobierno y, sobre todo, por las endebles condiciones de formalización de la tenencia, que ponen en riesgo el derecho al arraigo de su población.

Por otro lado, observamos que el estado impulsó una batería de leyes que habilitaron cambios en los usos del suelo y posibilitaron la venta de tierras públicas. Se espera que por esta imbricación entre intervención estatal e inversión privada el precio del suelo se dispare más temprano que tarde. Si bien estos efectos aún están por verse, el caso del Hospital Ferroviario marca una clara tendencia: en tan solo ocho años y con una simple operación de compra-venta, el grupo que vendió la parcela a los desarrolladores se hizo con una ganancia del 283 \% en dólares. La particularidad del barrio de Retiro es que hasta el año 2016 el precio del $\mathrm{m}^{2}$ no aparecía en los registros oficiales debido a que gran parte de su territorio era propiedad del estado o hábitat informal. El estado, desde entonces, se encargó de liberar tierra al mercado, y en el período bajo análisis (2015-2019) liberó 20,69 hectáreas (de las cuales ya se subastaron 3,27). Al ser una rehabilitación que se encuentra en etapa de gestación, aún no se evidencia una dinámica de población desplazada por otra de mayor estatus socioeconómico como para hablar de gentrificación. 
Si bien nos propusimos considerar al estado como un epicentro de disputas y no como una cosa en sí, notamos que en el período bajo análisis los instrumentos tendieron a favorecer, sin lugar a dudas, a los distintos capitales y no así a los habitantes de la Villa 31. En ese sentido, enumeramos un sinnúmero de herramientas que se utilizaron para favorecer tanto el capital fundiario como el inmobiliario y el financiero: desde privatizaciones de tierras estatales hasta facilidades para invertir en proyectos inmobiliarios, pasando por la delirante suma de dinero obtenida a través de empréstitos y volcada en Retiro que, en ausencia de mecanismos de captación de plusvalía, solo beneficiarán a quienes invirtieron en la zona.

En cuanto al rol de los organismos multilaterales de crédito (BID, BM y CAF), vemos una notable participación en cada uno de los grandes proyectos que se impulsaron en Retiro, al punto tal de que uno de ellos - el BID— decidió mudar sus oficinas allí. Los organismos han otorgado líneas de crédito para financiar un elevado porcentaje del monto destinado al Paseo del Bajo, el Conector Verde con el cambio de traza de la Illia y la urbanización de la Villa 31. Cabe resaltar la dinámica perniciosa que se puso en juego con estos préstamos, siendo la línea otorgada por el Paseo del Bajo la más emblemática: el GCBA tomó un crédito con la CAF y luego puso en subasta terrenos (en su mayoría de Retiro) para pagarlo. En este punto, las dimensiones de análisis propuestas se entrelazan: el estado hace obra pública para valorizar la zona, los organismos multilaterales de crédito se presentan como principales impulsores del proceso y en el marco del pago de las deudas se justifican las ventas de tierras.

Este trabajo se propuso explorar un escenario extremadamente complejo en el que diversos actores, a través de sus intervenciones en distintos niveles y con métodos diversos, buscan imponer, de alguna manera, un proyecto de ciudad. A cuatro años de su inicio, la rehabilitación de Retiro todavía es un proceso abierto. Con el cambio de gobierno a nivel nacional se judicializó y se detuvo el proceso de traspaso de terrenos a la CABA. A su vez, en el barrio Mugica los vecinos siguen pujando por la modificación de la escritura vigente (que podría atenuar el riesgo de desplazamiento vía mercado) y por encauzar diversos elementos de la política de integración.

\section{Referencias bibliográficas}

ARRIGHI, Giovanni (1999). El largo siglo XX. Dinero y poder en los orígenes de nuestra época. Madrid: Akal. 
BELLARDI, Marta y DE PAULA, Aldo (1986). Villas miseria: origen, erradicación y respuestas populares. Buenos Aires: Centro Editor de América Latina.

BLAUSTEIN, Eduardo (2006). Prohibido vivir aquí. Buenos Aires: Punto de Encuentro.

BRIKMAN, Denise (2016). ¿Gestión social de hábitat? La política del PRO en las villas de CABA, 2011-2015. Quid 16, Revista del Área de Estudios Urbanos del Instituto de Investigaciones Gino Germani de la Facultad de Ciencias Sociales (UBA), vol. 6, 1-26. Recuperado de: https://publicaciones.sociales.uba.ar/ index.php/quid16/article/view/2058/1763

CAPALBO, Tomás (2019). La participación en disputa: significados en pugna en el marco del proceso de urbanización de la Villa 31. Recuperado de: https://www. aacademica.org/000-023/229

CAPALBO, Tomás; SCHARAGER, Andrés y TOBIAS, Melina (2020). La nueva política de urbanización y el rol de los mecanismos participativos en las villas de la Ciudad de Buenos Aires. El caso de la Villa 31 (2015-2018). Buenos Aires: Ciccus. (En prensa).

CASGRAIN, Antoine y JANOSCHKA, Michael (2013). Gentrificación y resistencias en las ciudades latinoamericanas. El ejemplo de Santiago de Chile. Revista Andamios, $V(10)$, 19-44.

CASTELLS, Manuel (1974). La cuestión urbana. Madrid: Siglo XXI.

CORREA, Roberto Lobato (1993). O espaço urbano.Río de Janeiro: Editorial Ática. Traducido por Ricardo Apaolaza con la supervisión de Luis J. Domínguez Roca.

CRAVINO, María Cristina y PALOMBI, Ariel (2014). De la urbanización a la solución de mercado. Políticas públicas y nuevos desafíos en las villas de la zona sur de la ciudad de Buenos Aires. Recuperado de http://sedici.unlp.edu.ar/ handle/10915/55669

CRAVINO, María Cristina y PALOMBI, Ariel (2015). El macrismo ¿neoliberal? Política urbana en el sur de la Ciudad Autónoma de Buenos Aires. Cuadernos de vivienda y urbanismo, vol. 8 (N. ${ }^{\circ}$ 15), pp. 40-51. doi: 10.11144.

CUENYA, Beatriz (2012). Grandes Proyectos Urbanos, cambios en la centralidad urbana y conflictos de intereses. En Cuenya, B., Novais, P. y Vainer, C. (Comps.) Grandes Proyectos urbanos. Miradas críticas sobre la experiencia argentina y brasileña. Buenos Aires: Editorial Café de las Ciudades.

DE ANGELIS, Massimo (2012). Marx y la acumulación primitiva: El carácter continuo de los cercamientos capitalistas. Theomai, Estudios Críticos sobre Sociedad 
y Desarrollo, 26. Recuperado de: http://www.revista-theomai.unq. edu.ar/NUMERO\%2026/De\%20Angelis\%20-\%20Marx\%20y\%20la\%20 acumulaci\%C3\%B3n\%20primitiva.pdf

DEL SOLAR, Josefina (1999). Retiro. Apuntes sobre la historia de Buenos Aires. Buenos Aires: La gaceta del Retiro.

DOMÍNGUEZ ROCA, Luis Javier (2005). Centralidad y políticas urbanas. Reflexiones sobre el 'deterioro’ y la 'rehabilitación’. GEOUSP-Espaço e Tempo, vol. 9 (N.‥1), pp. 213-232. doi: 10.11606

GONÇALVES MENDES, Luís Felipe (2009). Gentrificación y rehabilitación urbana:la ambigüedad y la certeza en la afirmación de la ciudad contemporánea. Recuperado de: https://upcommons.upc.edu/bitstream/handle/2099/11941/05_ PROCEEDINGS_M5_06_0006.pdf

GONZÁLEZ REDONDO, Carolina (2014). La expulsión de lo indeseable. La Unidad de Control del Espacio Público como parte de la racionalidad política de la gestión del espacio urbano bajo el macrismo. Revista AVATARES de la comunicación y la cultura, 7. Recuperado de: https://publicaciones.sociales.uba. ar/index.php/avatares/article/view/4791

HARVEY, David (2004). El nuevo imperialismo: acumulación por desposesión. En Panitch, L. y Leys, C. (eds.) El nuevo desafío imperial. Buenos Aires: CLACSO.

HARVEY, David (2014). Ciudades rebeldes. Del derecho a la ciudad a la revolución urbana. Buenos Aires: Akal.

HERZER, Hilda (2008). Acerca de la gentrificación. En Herzer, H. (org.), Con el corazón mirando al sur. Transformaciones en el sur de la ciudad de Buenos Aires. Buenos Aires: Espacio Editorial.

HOLLOWAY, John (1993). La reforma del Estado: Capital global y Estado nacional. Recuperado de: https://cuadernosdelsurorg.files.wordpress.com/2017/06/ holloway_reformaestado.pdf

JANOSCHKA, Michael (2016). Gentrificación, desplazamiento, desposesión: procesos urbanos claves en América Latina. Revista INVI, vol. 31(n. 88), pp. 27-71.

LÓPEZ-MORALES, E.; ARRIAGADA-LUCO, C.; GASIC-KLETT, I. y MEZA-CORVALÁN, D. (2015) Efectos de la renovación urbana sobre la calidad de vida y perspectivas de relocalización residencial de habitantes centrales y pericentrales del Área Metropolitana del Gran Santiago. EURE, vol. 41 (N. $\left.{ }^{\circ} 124\right)$, pp. 45-67.

MAKHLOUF DE LA GARZA, Muna (2015). Aproximaciones a la gentrificación en el Río de 
Janeiro de los megaeventos deportivos. Actores, discusiones y resistencias. En Delgadillo, V., Días I. y Salinas L. (coords.), Perspectivas del estudio de la gentrificación en México y América Latina. México: UNAM.

MIGNAQUI, Iliana (2018). Buenos Aires en venta. Revista Voces en el fénix 8(71). Recuperado de: https://www.vocesenelfenix.com/content/buenos-aires-en-venta

OSZLAK, Oscar (2017). Merecer la ciudad. Sáenz Peña: UNTREF.

NASHED, Mirna (2018). The gentrification of West Chelsea. A history of a High Line and howit changed a city. Recuperado de: https://macaulay.cuny.edu/ eportfolios/vellon18/gentrification/mirnanashed/the-gentrification-ofwest-chelsea/

PARK, Robert Ezra (1999). La ciudad y otros ensayos de ecología urbana. Barcelona: Serbal.

SOCOLOFF, Ivana (2015). Capital inmobiliario-financiero y articulaciones públicoprivadas: consideraciones a partir del centro comercial Abasto de Buenos Aires. Recuperado de: https://www.academia.edu/38535784/Capital_ inmobiliario-financiero_y_articulaciones_p\%C3\%BAblico-privadas_ consideraciones_a_partir_del_centro_comercial_Abasto_de_Buenos_Aires

SMITH, Neil (2012). La nueva frontera urbana. Ciudad revanchista y gentrificación. Madrid: Traficante de sueños.

TOPALOV, Christian (1979). La urbanización capitalista: algunos elementos para su análisis. México: Edicol.

\section{Artículos periodísticos y documentos públicos}

Audiencia Pública. "Otorgar una concesión de uso a título gratuito a la Agencia deAdministración de Bienes del Estado Nacional -AABE-, para el funcionamiento de la sede del BID”. Disponible en: https://www. legislatura.gov.ar/audiencia/27\#prettyPhoto [03/12/2018].

Clarín (4 de septiembre de 2017). En la zona de Retiro hay 20.000 habitantes. Macri convoca al diálogo para erradicar la Villa 31. Recuperado de: https://www.clarin. com/ediciones-anteriores/macri-convoca-dialogo-erradicar-villa-31_0_ S18QmeyAFg.html

Clarín. Venderán tierras para urbanizar la villa 31 y pagar el Paseo del Bajo https:// www.clarin.com/ciudades/venderan-tierras-urbanizar-villa-31-pagarpaseo_0_g_JOixDzV.html [04/07/2019]. 
Infobae. Antes de dejar el poder, Macri autorizó al Correo Argentino a vender un emblemático inmueble en Retiro que vale al menos USD 17 millones https://www.infobae.com/economia/2020/03/02/antes-de-dejar-el-podermacri-autorizo-al-correo-argentino-a-vender-un-emblematico-inmuebleen-retiro-que-vale-al-menos-usd-17-millones/ [02/03/2020].

La Nación (24 de octubre de 2016). Villa 31: El trabajo silencioso de los que apuestan a un cambio. Recuperado de: https://www.lanacion.com.ar/1949817-villa-31-eltrabajo-silencioso-de-los-que-apuestan-a-un-cambio

ConstruAr (2 de marzo de 2017). Larreta confirmó que la nueva autopista Illia costará 1700 millones y con la vieja harán una High Line como en Nueva York. Recuperado de: http://www.construar.com.ar/2017/03/3287-larreta-confirmo-que-lanueva-autopista-illia-costara-1700-millones-y-con-la-vieja-haran-una-highline-como-en-nueva-york/

La Nación (28 de septiembre de 2018) Ciudad: Paseo del Bajo, la obra más imponente y costosa de la última década. Recuperado de: https://www.lanacion. com. ar/sociedad/ciudad-obras-paseo-del-bajo-y-otros-proyectos-costososultima-decada-nid2175899

La Política Online (3 de febrero de 2018). Quieren que el parque lineal de la Illia incluya un museo como la High Line de Manhattan. Recuperado de: https://www. lapoliticaonline.com/nota/111068-quieren-que-el-parque-lineal-de-laillia-incluya-un-museo-como-la-high-line-de-manhattan/

Página 12 (3 de junio de 2019). La villa 31 quedará en venta al mejor postor. Recuperado de: https://www.pagina12.com.ar/199996-la-villa-31-quedara-en-venta-almejor-postor

Perfil (16 de junio de 2018). Frenan hasta 2019 las obras para "mover" la autopista Illia. Recuperado de: https://www.perfil.com/noticias/sociedad/frenan-hasta2019-las-obras-para-mover-la-autopista-illia.phtml

Gobierno de la Ciudad Autónoma de Buenos Aires (29 de julio de 2019). Resolución $n^{\circ}$ 204/SECISYU/19. Recuperado de: https://documentosboletinoficial. buenosaires.gob.ar/publico/ck_PE-RES-MJGGC-SECISYU-204-19-5674.pdf

Tiempo Argentino (20 de mayo de 2017). Puerto Retiro: otro meganegocio que Caputo cerró con ayuda del Estado. Recuperado de: https://www.tiempoar.com.ar/nota/ puerto-retiro-otro-meganegocio-que-caputo-cerro-con-ayuda-del-estado 